\title{
Mechanical Properties of GFR \& Graphite Epoxy Polymer Composites
}

\author{
A.Aakash ${ }^{1}$, S.Selvaraj ${ }^{2}$ \\ ${ }^{1}$ PG Scholar Department of Mechanical Engg., ACGCET, Karaikudi- 630003, \\ Tamil Nadu, INDIA. \\ ${ }^{2}$ ASSISTANT PROFESSOR Department of Mechanical Engg., ACGCET, Karaikudi -630003, \\ Tamil Nadu, INDIA.
}

\begin{abstract}
Composite materials have the great potential and widely used as building material in numerous applications. Polymer composite material obtains the necessary properties in a controlled significant degree by the selection of strands and lattice. The properties of the materials have been selected by choosing the correct proportion of matrix and reinforcements. To build the quality of the material by expanding the fiber substance of the material. In this current examination, the mechanical properties of the glass fiber and graphite is strengthened with epoxy polymer composite were considered. Here the open embellishment method was received for the manufacture of the polymer composite The mechanical properties, for example, rigidity, compression quality, sway quality and water ingestion test was resolved according to the ASTM norms. The mechanical properties were improved as the filaments support content expanded in the grid material.
\end{abstract}

Keywords:- Glass Fiber, Graphite, Epoxy Resin, Hand Lay-Up Technique.

\section{INTRODUCTION}

This paper shows that the mixing of manufactured filaments in half and half composites has progressively applied in a few unique fields of building and innovation. In automobile industries, steels are also used in car bumpers. In this present work, steel is replaced with composite material. Composites are overwhelming the business. The quality of the composites relies upon the attributes of the support and the network stages. Further expansion of particles (Hardener) into the grid improves the general properties and attributes of the composite material. The flow inquire about includes the manufacture of the glass fiber strengthened, graphite composites with epoxy gum particles in the lattice utilizing hand lay-up process. A composite material (likewise called a synthesis material or abbreviated to composite, which is the basic name) is a material produced using at least two constituent materials with fundamentally unique physical or compound properties that, when joined, produce a material with qualities not the same as the individual segments. K.Naresh Kumar [1] investigated the mechanical properties of the glass fiber polymer matrix with reinforcement of coal ash. In this composite material is to increase and enhance the elastic modulus and tensile strength with increasing the glass fiber content. However, the rupture behaviour changes from ductile to brittle. However increasing the fiber content decreases ductile content of the material. Elanchezhian C [2] conducted a work on varying strain rates and temperatures on the materials of glass and carbon fiber reinforced polymer composites in order to analyse the mechanical behaviour of the composite material. Here the force versus displacement and time versus force curves for each case have been drawn. The impact strength has the significant effect on the material as the material strength has decreased due to less amount of fiber content on the particular composite material. Hence increasing the fiber content will increases the strength of the material. Jacob Olaitan Akindapo [3] evaluated the mechanical properties of coconut shell fibers as reinforcement material and epoxy resin as the matrix material and fabricated the composite material using compression moulding technique. Mechanical properties, for example, rigidity, pressure quality, flexural quality, and effect quality are assessed. The interfacial properties, inward splits, and inner structure of the cracked surfaces are assessed by utilizing SEM. The last explanation showed that the joining of coconut shell filaments with epoxy pitch can improve the properties of the composite material. T.D. Jagannatha [4] experiment on the mechanical properties of carbon/glass fiber strengthened epoxy half breed polymer composites. At first the materials contain the carbon fiber and glass filaments are fortifications and epoxy half and half tar are utilized as lattice. The mechanical properties, for example, elasticity and hardness are assessed. The small-scale hardness of carbon fiber fortified composite is higher than different composites. The malleability of carbon fiber strengthened composite is higher than different composites. Akar Dogan [5] variety of the mechanical properties of E-glass/epoxy composites is exposed to aqueous maturing. The vacuumhelped tar implements forming was utilized to make composites. In assembling of composites, unidirectional Eglass textures with areal thickness of $300 \mathrm{~g} / \mathrm{m} 2$ and a pitch framework (Araldite LY 564/Aradur 3487 BD) were utilized. To decide the mechanical properties, for example, modulus of versatility, longitudinal, and transverse quality, shear quality and Poisson's proportion of the composite materials are directed. The ingested vitality increment for $100 \mathrm{~h}$ matured examples and the assimilated vitality generally stays steady until $800 \mathrm{~h}$ and afterward diminishes. Most extreme contact power and deflection are of comparable conduct. 


\section{METHODOLOGY}

The glass fiber, graphite and epoxy are the selected materials as per the above studies. To create the composite material hand-lay-up strategy is reasonable for the chosen type pitch superior to other embellishment method To avoid resin air gap caused during the curing process can cause low bonding between the resin and reinforcement materials.

\section{$>$ Fabrication of composites:}

Mould made of mild steel was used with dimensions of $300 \times 300 \times 10 \mathrm{~mm}$ of each specimen for tensile test this method is the cheapest method of manufacturing the quality of the composite depends on the skills. Gel coat is first applied to the form utilizing a splash firearm for a topnotch surface. At the point when the gel coat has relieved move stock glass fiber fortification is physically positioned on the shape

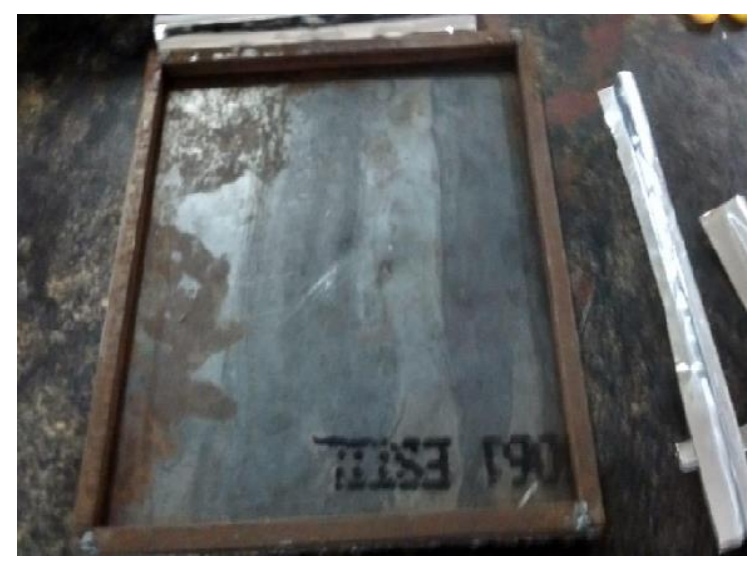

Fig 1:- Mould plate

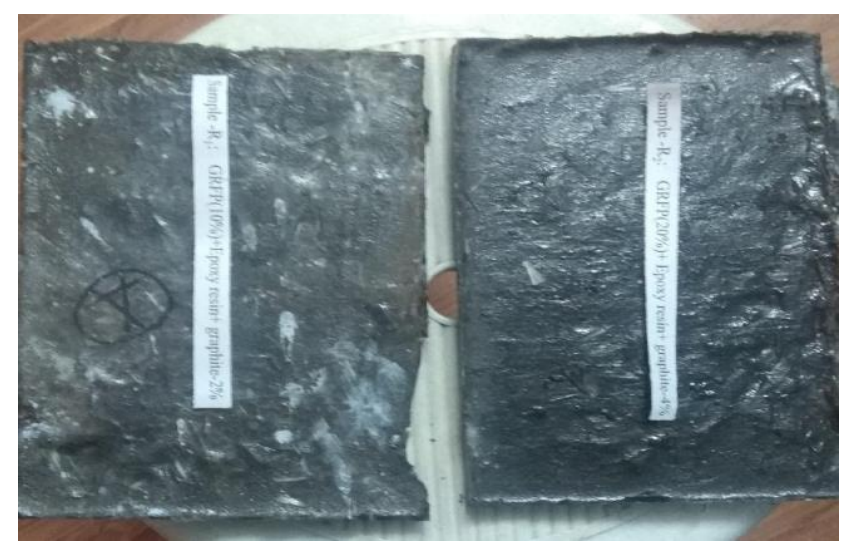

Fig 2:- Composite plates

The covering gum is applied by pouring, brushing, splashing, or utilizing a paint roller. FRP rollers, paint rollers are utilized to unite the cover, wetting the support and expelling ensnared air. Then the second layer of the graphite reinforcement is mixed with resin and is poured above the previous layer. Then another layer of glass fiber reinforcement is added to build laminate thickness. Then the material is then placed in the open atmosphere for the curing process. Two identical specimens were preparing at various compositions.

\section{SPECIMEN PREPARATION}

The glass fiber and graphite fiber strengthened epoxy composite pieces were taken out from the form and afterward the examples were cut into appropriate measurements according to the ASTM standards according to different mechanical testing. Using the different tools in the workshop the test specimen was cut from the composite slabs. Here ASTM standard a370 is used for mechanical testing for tensile, compression and impact testing of the composite material.

\section{TESTING OF THE COMPOSITE MATERIALS}

The mechanical properties of the composite were assessed by tractable, pressure, effect, and water assimilation estimations. The examples are set up from the manufactured composites and the edges are done by utilizing record and Emery sheet. Pliable testing was inspected by ASTM a370. The examples were stacked between two physically movable grippers of $60 \mathrm{KN}$ on the mechanized all-inclusive testing machine with an electronic extensometer which is used for measuring the elongation of the gauge length. The load is applied until the material gets fractured. Here the elongation, maximum load, initial and final gauge length of the specimen is recorded. The test was rehashed for another example and the normal was taken from the elasticity of the composite material. Compression testing was examined same as ASTM a370. The specimens were loaded between the plates of the universal testing machine. Here the material experiences the opposing forces that the forces which acts inwards through the specimen. Impact testing was examined according to ASTM a370. Here izod testing machine is used for impact test. The center of the specimen was cut into $\mathrm{V}$-notch and the position of the specimen is placed vertically. Direction of the notch face is placed in front of the striker. The striking point of the specimen is the upper tip. This is also called as pendulum testing machine. Water absorption testing shows that the material capability to withstand amount of water can absorb with in the period of time under specific conditions. The standard used for water adsorption is ASTM D570. The equipment used to measure the weight is mettler balance. The specimen is dried in a broiler for a predetermined time and temperature and the set in a desiccator for cooling the example. The examples are weighed before testing. At that point the material is risen in water at covetousness upon conditions for $48 \mathrm{hrs}$ and 96hrs. At that point the examples are evacuated tapped dry with a buildup free material and gauged. 


\section{RESULT AND DISCUSSION}

A. Tensile strength:

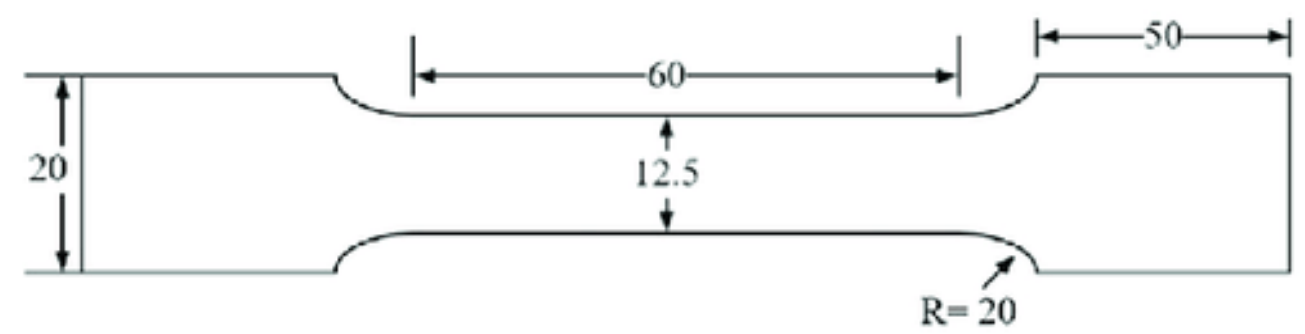

Fig 3:- tensile specimen dimensions

The pliable test was performed distinctly on the level composite example. The components of the example according to the ASTM standard are appeared in the above figure. The test was performed for four samples and the average value is taken for analysis.

\begin{tabular}{|c|c|c|c|c|c|c|c|c|}
\hline Ratio & $\begin{array}{c}\text { Thick } \\
\mathbf{m m}\end{array}$ & $\begin{array}{c}\text { Width } \\
\mathbf{m m}\end{array}$ & $\begin{array}{c}\text { Cross } \\
\text { Sectional } \\
\text { Area } \\
\mathbf{m m}^{2}\end{array}$ & $\begin{array}{c}\text { Total } \\
\text { Load } \\
\mathbf{K N}\end{array}$ & $\begin{array}{c}\text { Tensile } \\
\text { Strength } \\
\mathbf{N} / \mathbf{m m}^{2}\end{array}$ & $\begin{array}{c}\text { Initial } \\
\text { Gauge } \\
\text { Length } \\
\mathbf{m m}\end{array}$ & $\begin{array}{c}\text { Final } \\
\text { Gauge } \\
\text { Length } \\
\mathbf{m m}\end{array}$ & $\begin{array}{c}\text { Percent } \\
\text { Elongation } \\
\mathbf{\%} \mathbf{E}\end{array}$ \\
\hline \multirow{2}{*}{$\mathbf{R}_{\mathbf{1}}$} & 10.91 & 19.67 & 214.60 & 6.57 & 30.62 & 50.00 & 51.34 & 2.68 \\
\cline { 2 - 9 } & 10.73 & 17.24 & 184.99 & 6.95 & 37.57 & 50.00 & 51.24 & 2.48 \\
\hline \multirow{2}{*}{$\mathbf{R}_{\mathbf{2}}$} & 12.59 & 18.62 & 234.43 & 8.24 & 35.15 & 50.00 & 50.97 & 1.94 \\
\cline { 2 - 9 } & 11.97 & 18.43 & 220.61 & 9.24 & 41.88 & 50.00 & 50.87 & 1.74 \\
\hline
\end{tabular}

Table 1:- tensile strength tabulation

In this analysis the second specimen has the high tensile strength than the first specimen due to the variation of reinforcement such as increasing the graphite powder and decreasing the glass fiber content so that the second specimen can withstand load than the first specimen. This shows that the increasing the reinforcement will increasing the strength of the material.

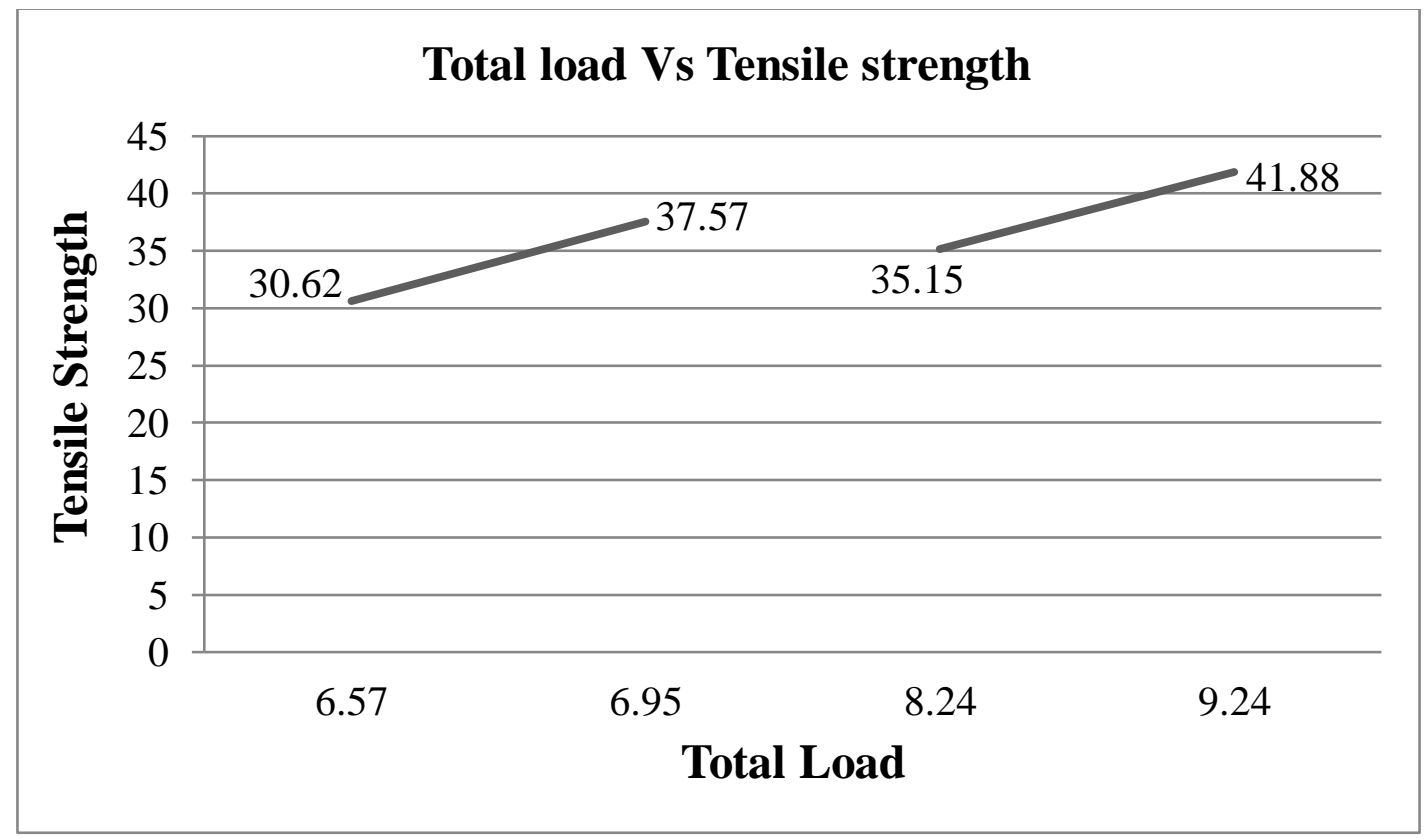

Fig 4 


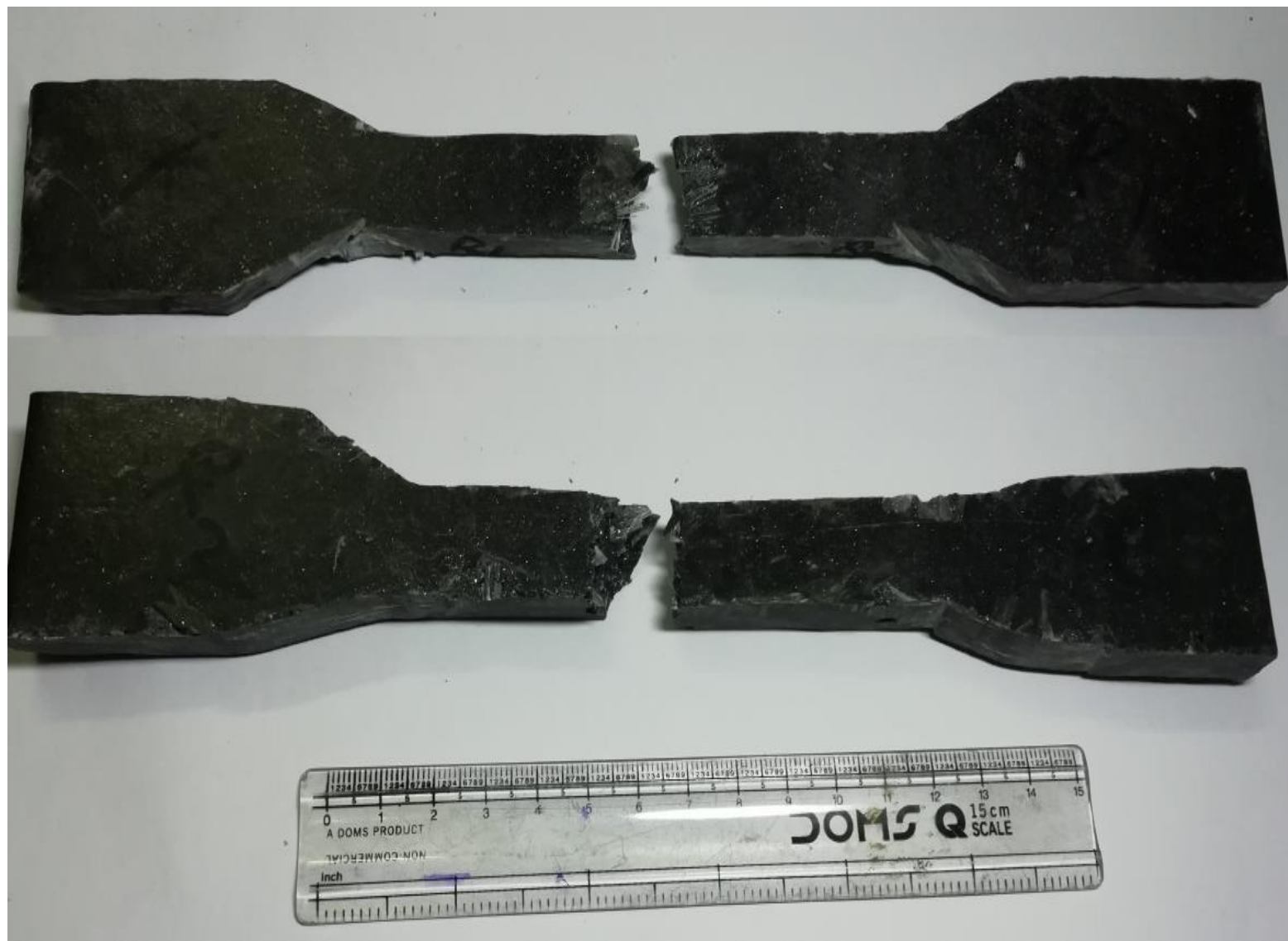

Fig 5:- Tensile Specimen-1

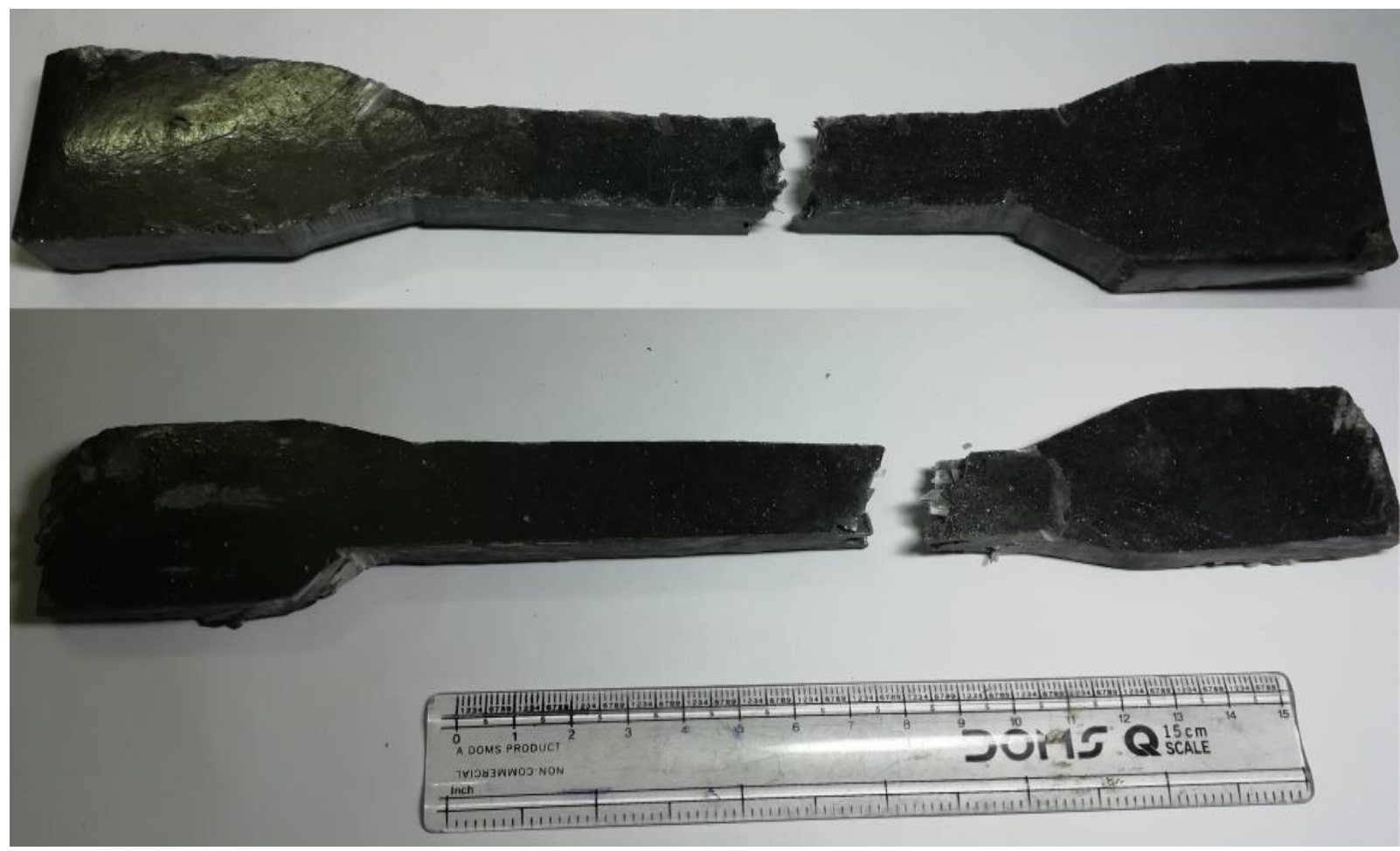

Fig 6:- Tensile Specimen-2 


\section{B. Impact strength:}

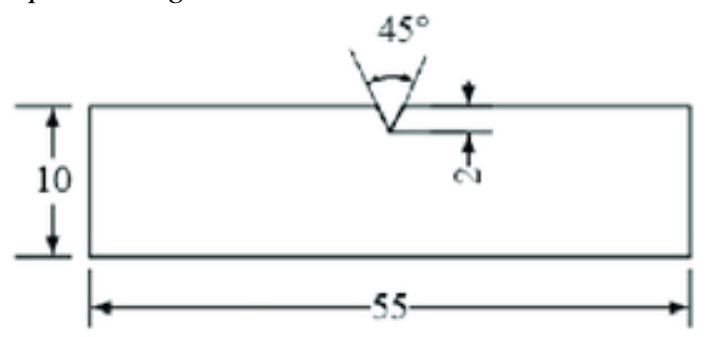

Fig 7:- impact specimen dimensions

Effect test was proceeded according to the ASTM standard appeared over the figure. In this impact test the specimen is $\mathrm{V}$-notched at the center of the specimen in one side and the other side is left as plain surface. The specimen is placed on the izod testing machine, notch face is placed in front of the striker. The striker is lifted at an angle of 45 and then the striker is locked up. When the lock is released the striker hits the upper part of the specimen. Then the impact values re measured in joules and noted down.

\begin{tabular}{|c|c|c|}
\hline S NO & SAMPLE & IZOD IMPACT VALUE IN (J) \\
\hline 1 & SPECIMEN 1 & 5 \\
\hline 2 & SPECIMEN 2 & 8 \\
\hline
\end{tabular}

Table 2:- impact strength tabulation

From the above analysis the second specimen requires more joules to break the specimen than the first specimen. So that mixing ratio of the second specimen gives more strength then the first specimen ratio.

\section{Compressive strength:}

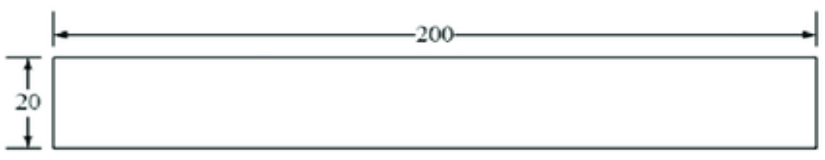

Fig 8:- compression specimen dimensions

A pressure test is any test wherein a material encounters contradicting powers that push internal upon the example from inverse sides or is in any case compacted, crushed, squashed, or straightened. Reason for pressure tests is to decide the conduct or reaction of a material while it encounters a compressive burden by estimating central factors, for example, strain, stress, and disfigurement. The ASTM for compression test is a370.

\begin{tabular}{|c|c|c|}
\hline S.No & COMPOSITION & Compression Strength N/mm \\
\hline 1 & SPECIMEN 1 & 50.20 \\
\hline 2 & SPECIMEN 2 & 55.18 \\
\hline
\end{tabular}

Table 3:- compressive strength tabulation

From the above analysis the second specimen gives the high compressive strength than the first specimen. So that the second specimen mixing ratio is better than the first specimen.

\section{Water retention:}

Water retention test is utilized to decide the measure of water ingested under the particular conditions. The factor that affects the water absorption is the type of plastics used, additives added, temperature available, and the length of the exposure. The ASTM standard used for water absorption is D570. The specimen is then dried on the oven and weighted in the mettler balance then immersed in the liquid placed at the room temperature for $48 \mathrm{hrs}$ and $96 \mathrm{hrs}$. Then the specimen is weighted at $48 \mathrm{hrs}$ and $96 \mathrm{hrs}$. Then compare before water absorption weight and after water absorption weight and the results are noted in the tabular column.

\begin{tabular}{|c|c|c|c|c|}
\hline S.no & SPECIMENS & $\begin{array}{c}\text { Weight before } \\
\text { test in gm }\end{array}$ & $\begin{array}{c}\text { Weight after test in gm } \\
\text { (48hrs) }\end{array}$ & $\begin{array}{c}\text { Weight after test in gm } \\
\text { (96hrs) }\end{array}$ \\
\hline 1. & SPECIMEN1 & 9.60 & 9.67 & 9.68 \\
\hline 2. & SPECIMEN 2 & 11.09 & 11.18 & 11.19 \\
\hline
\end{tabular}

Table 4:- water retention tabulation

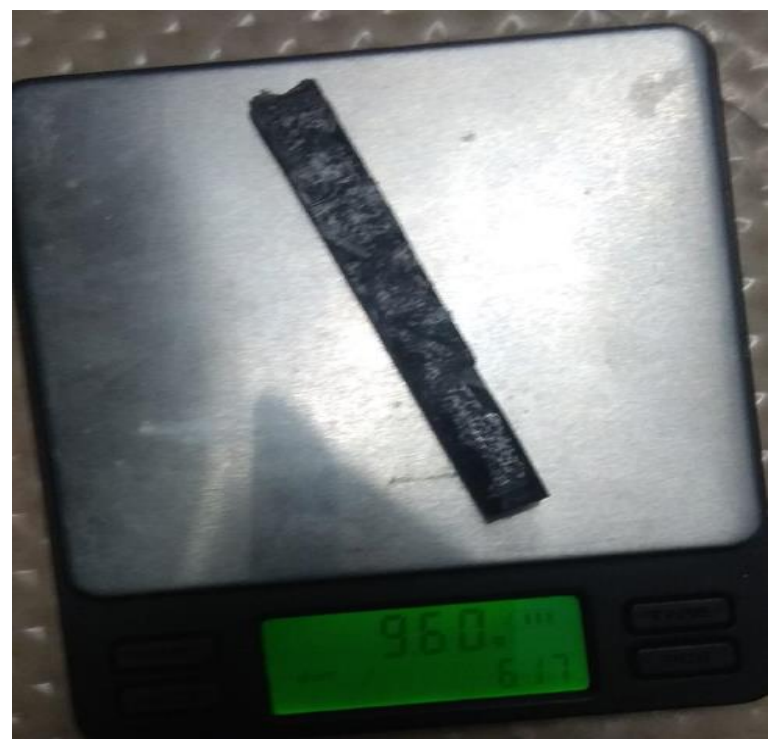

Fig 9:- specimen 1

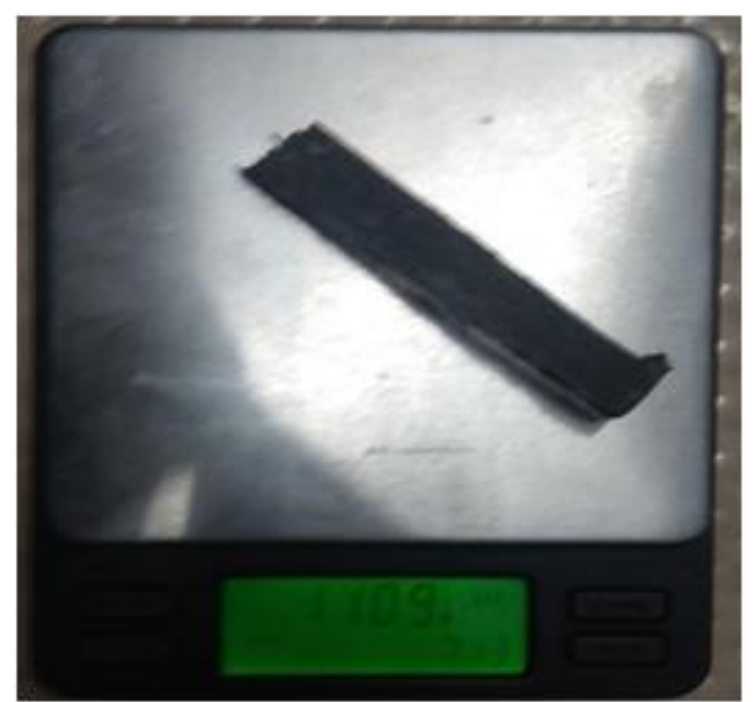

Fig 10:- specimen 2 


\section{CONCLUSION}

Fiber strengthened composite are one of the blasting materials in aviation, car, marine, development, and building Enterprises. In which Glass strands are playing a fundamental job in fiber fortified composite as a result of its great mechanical properties. In this part the ends are made by the outcome got by examination of glass fiber/graphite fortified polymer composite. Examinations are done by ductile, pressure, effect, and water assimilation testing. The following conclusions can be drawn from the present investigation.

The second mixing ratio of glass fiber $(20 \%)+$ Epoxy resin+ graphite $(4 \%)$ Shows higher tensile, compressive strength, maximum impact strength and high water absorption rate from these investigations. Due to higher volume of reinforcements in the specimen induces the mechanical properties.

\section{REFERENCES}

[1]. K.Naresh Kumar, M.Prasanth kumar, V. Krishna, D.Srinivasa Rao (2013), "Experimental Investigation on Mechanical Properties of Coal Ash Reinforced Glass Fiber Polymer Matrix Composites", IJETAE, ISSN 2250-2459.

[2]. Elanchezhian C, Ramnath BV, Hemalatha J (2014) "Mechanical behaviour of glass and carbon fiber reinforced composites at varying strain rates and temperatures", Procedia Materials Science vol. 6, No. 1405-18.

[3]. Jacob Olaitan Akindapo, Ayogu Harrison, Olawale Monsur Sanusi (2014) "Evaluation of Mechanical Properties of Coconut Shell Fibers as Reinforcement Material in Epoxy Matrix”, IJERR, Vol. 3 ISSN 23372348.

[4]. T.D.Jagannatha and G Harish (2015) "Mechanical Properties Of Carbon/Glass Fiber Reinforced Epoxy Hybrid Polymer Composites", IJMERR Vol. 4, No. 2

[5]. Akar Dogan, and Cesim Atas (2016) "Variation of the mechanical properties of E-glass/epoxy composites subjected to hydrothermal aging", Journal of composite materials, Vol. 7 no. 637-646

[6]. Ramesh Kumar, Kishore Kumar Mahato, and Bankim Chandra Ray (2016) "Water absorption behavior, mechanical and thermal properties of nano $\mathrm{TiO} 2$ increased fiber bolstered compound composites", Composites of a engineering science and production, ISSN: 736-747.

[7]. Getahun Aklilu, Sarp Adali, Glen Bright (2017) "Temperature effect on mechanical properties of carbon, glass and hybrid polymer composite specimens", IJERR Vol. 39, No. 119-125.

[8]. M. D. Kiran, H. K.Govindaraju , T. Jayaraju (2018) "Evaluation of Mechanical Properties of Glass Fiber Reinforced Epoxy Polymer Composites with Alumina, Titanium dioxide and Silicon Carbide Fillers", ELSEVIER ISSN:22355-22361
[9]. Akula Swathi, S.Bhanu Murthy, K.Nagendra Babu (2019) "Evaluation of Mechanical Properties of GFRP Composites with Fillers", IJITEE Vol. 8 Issue11

[10]. Sutrisno, Sutomo, Sudarno, and T.Tristono (2019)"Study on Mechanical Properties of Composite Geomaterial Powder Waste Tiles and Glass Fiber", AIMS Materials Science vol.6 